\title{
Bankalarda Etkinliğin Veri Zarflama Analizi ile Değerlendirilmesi: Türkiye'deki Kamu, Özel ve Yabancı Sermayeli Bankalar Üzerine Karşılaştırmalı Bir Araştırma (Evaluating Banks' Efficiency Using Data Envelopment Analysis: A Comparative Research on Public, Domestic Private and Foreign Banks in Turkey)
}

\section{Mehmet Sabri TOPAK (iD a Yavuz ALACAATLI iD b}

a İstanbul Üniversitesi, İktisat Fakültesi, İşletme Bölümü, İstanbul, Türkiye. msabri@istanbul.edu.tr

b Halkbank, Vergi Yönetimi ve Ödemeler Daire Başkanlığı, İstanbul, Türkiye. yavuz.alacaatli@halkbank.com.tr

\begin{tabular}{|c|c|}
\hline MAKALE BİLGİSİ & ÖZET \\
\hline Anahtar Kelimeler: & $\begin{array}{l}\text { Amaç - Türkiye'de faaliyet gösteren mevduat bankalarının etkinliğinin araştırılması ve sermaye } \\
\text { sahipliği açısından etkinliklerinin karşılaştırılmasıdır. }\end{array}$ \\
\hline $\begin{array}{l}\text { Banka } \\
\text { Veri Zarflama Analizi } \\
\text { Türkiye }\end{array}$ & $\begin{array}{l}\text { Yöntem - Veri Zarflama Analiz yönteminin uygulandığı araştırmada Faiz Giderleri, Diğer Faaliyet } \\
\text { Giderleri ve Özkaynaklar kalemleri girdi; Faiz Gelirleri ile Alınan Ücret ve Komisyon kalemleri ise } \\
\text { çıktı değişkenleri olarak seçilmiştir. Analizde üç adet kamusal sermayeli, beş adet özel sermayeli ve } \\
\text { dört adet yabancı sermayeli banka olmak üzere toplam } 12 \text { mevduat bankasının 2010-2017 dönemine } \\
\text { ilişkin verileri kullanılmıştır. }\end{array}$ \\
\hline $\begin{array}{l}\text { Gönderilme Tarihi } 10 \text { Ekim } \\
2020 \\
\text { Revizyon Tarihi } 3 \text { Aralık } 2020 \\
\text { Kabul Tarihi } 20 \text { Aralık } 2020\end{array}$ & $\begin{array}{l}\text { Bulgular - Bankaların 2010-2017 faaliyet dönemine ilişkin ortalama etkinlik değeri 0,983 olarak } \\
\text { gerçekleşmiştir. Ortalama etkinlik değeri kamusal sermayeli bankalarda 0,987; özel sermayeli } \\
\text { bankalarda 0,970; yabancı sermayeli bankalarda 0,997'dir. Çalışma kapsamındaki bankaların etkin } \\
\text { olduğu dönem sayısının toplam dönem sayısı içindeki oranı \% 75'dir. Bu oran yabancı sermayeli } \\
\text { bankalarda \% 84, kamusal sermayeli bankalarda \% 79, özel sermayeli bankalarda ise \% } 65 \text { olarak } \\
\text { gerçekleşmiştir. }\end{array}$ \\
\hline $\begin{array}{l}\text { Makale Kategorisi: } \\
\text { Araştırma Makalesi }\end{array}$ & $\begin{array}{l}\text { Tartışma - Özel sermayeli bankalar grubunun ortalama etkinlik değerinin ve etkin olduğu dönem } \\
\text { sayısının toplam dönem sayısı içindeki oranının kamusal sermayeli bankalar ve yabancı sermayeli } \\
\text { bankalara göre görece düşük olmasının nedeni, Türkiye İş Bankası A.Ş.'nin çalışma kapsamındaki } \\
\text { tüm dönemlerde etkinlik değerinin düşük olması ve teknik olarak etkin olmamasıdır. Türkiye İş̧̧ } \\
\text { Bankası A.Ş. analiz dışında bırakıldığında, sermaye sahipliği türüne göre Türkiye'de faaliyet } \\
\text { gösteren mevduat bankalarının etkinliklerinde fark yaratacak derecede önemli bir bulguya } \\
\text { rastlanmamıştır. }\end{array}$ \\
\hline ARTICLE INFO & ABSTRACT \\
\hline & $\begin{array}{l}\text { Purpose - To investigate the efficiency of deposit banks in Turkey and to compare their efficiency } \\
\text { in terms of capital ownership. }\end{array}$ \\
\hline $\begin{array}{l}\text { Banks } \\
\text { Data Envelopment Analysis } \\
\text { Turkey }\end{array}$ & $\begin{array}{l}\text { Design/methodology/approach - Data Envelopment Analysis method was applied in the research. } \\
\text { Interest Expenses, Other Operating Expenses and Shareholders'Equity were selected as input } \\
\text { variables while Interest Income and Fees and Commissions Income were used as outputs. The study } \\
\text { consists of } 12 \text { deposit banks, including three state-owned, five privately-owned and four foreign- } \\
\text { owned banks and it covers the } 2010 \text { - } 2017 \text { period. }\end{array}$ \\
\hline $\begin{array}{l}\text { Received } \\
\text { Revised } \\
\text { Accepted }\end{array}$ & $\begin{array}{l}\text { Findings - The average efficiency value of banks for the } 2010-2017 \text { operating period is } 0.983 \text {. } \\
\text { Average efficiency value is } 0,987 \text { in state-owned banks; } 0.970 \text { in private banks; } 0.997 \text { in foreign banks. } \\
\text { The banks have on average } 75 \% \text { operating efficiency in the periods covered by the study. This ratio } \\
\text { is } 84 \% \text { in foreign banks, } 79 \% \text { in state-owned banks and } 65 \% \text { in private banks. }\end{array}$ \\
\hline $\begin{array}{l}\text { Article Classification: } \\
\text { Research Article }\end{array}$ & $\begin{array}{l}\text { Discussion - The average efficiency value of the private banks group and the ratio of the number of } \\
\text { periods in which operating effectiveness in the total number of periods is relatively lower than state- } \\
\text { owned banks and foreign banks. This is caused by the fact that Türkiye İş Bankası A.Ş. has low } \\
\text { efficiency value and is technically ineffective in all periods covered in the study. When Türkiye İş } \\
\text { Bankası A.Ş is excluded from the analysis no significant findings were reached that can lead to a } \\
\text { difference in the efficiency of Turkish deposit banks in terms of ownership structure. }\end{array}$ \\
\hline
\end{tabular}




\section{GİRISs}

Ülke ekonomilerinin gelişmesi açısından finansal sistemin etkin bir şekilde çalışmasının önemi büyüktür. Finansal sistemdeki gelişmenin ekonomik büyüme üzerinde olumlu yönde etkisinin bulunduğuna yönelik bulgulara ulaşan çok sayıda çalışma (Demirgüç -Kunt vd., 2012; King ve Levine 1993; Apergis vd., 2007) bulunmaktadır. Bu çalışmalarda genel olarak finansal gelişme göstergeleri ile ekonomik büyüme göstergeleri arasında uzun dönemli ve pozitif yönlü bir ilişki olduğu ampirik olarak kanıtlanmıştır (Pradhan vd., 2014). Söz konusu çalışmaların sonuçlarına göre finansal sistemi oluşturan finansal kurumların ve finansal piyasaların işleyişinde meydana gelen olumlu gelişmeler ülke ekonomilerinde refah düzeyinin artırmasına katkıda bulunmakta ve "daha fazla finansal gelişme, daha fazla ekonomik büyüme" şeklindeki görüş genellikle geçerli olmaktadır (Law ve Singh, 2014).

Ekonomide fon fazlası olan birimler ile fon talep eden birimler arasındaki fonların akışkanlığının sağlanmasında finansal aracılık görevini yerine getiren bankalar, üstlendikleri işlevler bakımından finansal sistemin merkezinde yer alan kurumlardır. Bankacılık sektöründe meydana gelen gelişmeler sadece bankaları değil ülke ekonomisindeki tüm sektörleri derinden etkileyebilmektedir (Saldanlı ve Aydın, 2016). 2001 yılında Türkiye'de gerçekleşen ekonomik krizin başlangıcında bankacılık sektöründe ortaya çıkan likidite krizi bulunmaktadır. 1980 yılında serbest piyasa ekonomisine geçen Türkiye'de 2001 ekonomik krizi etkileri bakımından son 40 yıllık dönemde gerçekleşen en önemli ekonomik kriz olarak kabul görmektedir. Ekonominin gelecekte bir daha benzer bir durum ile karşılaşmaması amacıyla ekonomi yönetimi tarafından 2001 yılı Nisan ve Mayıs aylarında sırasıyla "Güçlü Ekonomiye Geçiş Programı" ve "Bankacılık Sektörü Yeniden Yapılandırma Programı" uygulamaya konulmuştur. Bu programların amacl, kamuya bütçe disiplininin getirilmesi ve bankacılık sektörünün yapılandırılması için alınan tedbirlerle sektöre olan güvenin sağlanmasıdır. Türkiye ekonomisinde bu süreçte yaşanan gelişmeler, güçlü bir ekonomiye sahip olabilmenin en önemli gereksinimlerinden bir tanesinin güçlü bir bankacılık sistemine sahip olunması gerektiğini göstermiştir (Topak ve Çanakçıŏlu, 2019). Bankacılık sektörüne yönelik olarak 2001 yılında gerçekleştirilen yapısal reformlarla Türkiye'de faaliyet gösteren bankaların finansal yapısı önemli ölçüde güçlendirilmiştir.(Turgut ve Ertay, 2016; Arabac1, 2018). Bu dönemde özellikle risk yönetimi ve denetim alanında getirilen reform niteliğindeki yenilikler ile Basel kriterlerinin uygulanmaya konulması sonucunda sektörün krizlere karşı direnci artmıştır.

Türkiye'de finansal sektör içinde bankaların önemli bir ağırlığı bulunmaktadır. Aktif büyüklüğü açısından finansal sektörün \% 90,5'lik kısmının denetim ve gözetiminden sorumlu kurum olan BDDK (Bankacilık Düzenleme ve Denetleme Kurumu)'nın 2018 yılı faaliyet raporuna göre finansal sektörün toplam aktifleri içinde Türk bankacıllk sektörünün payı \% 87,2' dir. Türkiye'de finansal sektörün aktif büyüklüğü 2018 yılsonu itibarıla yaklaşık 839 milyar ABD doları düzeyindedir. Bu tutar GSYH'nin yaklaşık 1,2 katı büyüklüğündedir. (BDDK, 2018-a,18).

Bankacılık sektörünün finansal kesim ve ekonomi açısından önemi düşünüldüğüne, sektördeki gelişmenin ekonomik büyüme üzerindeki etkisini araştırmak amacıyla yapılan çok sayıda çalışma bulunmaktadır. Bu çalışmalardan elde edilen bulgulara göre sektördeki gelişme ekonomik büyümeyi genellikle pozitif yönlü etkilemektedir (Beck ve Levine ,2004). Finansal aracılık görevini yerine getiren bankaların ekonomideki işlevi nedeniyle, banka performansı ve etkinliği üzerine yapılan çalışmalar uzun süredir güncelliğini korumakta ve araştırmacıların ilgisini çekmektedir. Bankaların etkinlik düzeylerini belirlemek amacıyla yapılan çalışmalar incelendiğinde oldukça geniş bir literatür bulunmaktadır. Bu çalışmalarda yer alan tartışmaların odağında ise analizde kullanılan girdi ve çıtı değişkenlerinin belirlenmesi önemli bir yer tutmaktadır (Çelik ve Kaplan, 2010).

Tüm ticari şirketlerde olduğu gibi bankalar açısından da faaliyet dönemine ilişkin azami kar hedefi bulunmaktadır. Mümkün olan minimum seviyede girdi kullanılarak mümkün olan azami çıktının elde edilmesi olarak ifade edilen etkinlik kavramı ile azami kar hedefi bir araya getirildiğinde bankalarda etkinlik, minimum gidere katlanılarak azami gelir elde etmek olarak tanımlanabilir. Ancak çalışmanın literatür incelemesi bölümünde de belirtildiği üzere konu üzerine yapılan çalışmalarda genellikle bankaların seçilmiş bazı bilanço kalemleri (mevduat, krediler, aktif toplam), işgücü sayısı ve şube sayısı gibi değerleri girdi ve (veya) çıktı değişkenleri olarak kullanılmaktadır. Bu noktada bizim görüşümüz mevcut çalışmalardan farklılaşmaktadır. Şirketler dönem içinde gelir elde etmek amacıyla giderlere katlanmakta ve faaliyetlerine 


\section{S. Topak - Y. Alacaatlı 12/4 (2020) 4340-4350}

ilişkin sonuçları da gelir tablosunda yer almaktadır. Bu nedenle faaliyet etkinliğinin ölçülmesinde kullanılması gereken değişkenlerin döneme ilişkin giderler ve gelirler arasından seçilmesi kanaatimizce daha doğru bir yaklaşım olmaktadır. Çalışmada bankaların esas faaliyetlerine ilişkin giderleri girdi, gelirleri ise çıktı değişkenleri olarak kullanılmıştır. Çalışma bu yönüyle konuya ilişkin önceki çalışmalardan farklılaşmaktadır. Alternatif maliyeti düşünülerek Özkaynaklar kalemi de girdi olarak kullanılmıştır.

Türkiye'de faaliyet gösteren bankaların etkinliklerini tespit etmek ve sermaye sahipliğine göre bankaların etkinliklerini değerlendirmek amacıyla yapılan çalışma, yedi bölümden oluşmaktadır. Giriş kısmı, literatür incelemesi ve araştırmanın amacı sırasıyla ilk üç bölümü oluşturmaktadır. Dördüncü ve beşinci bölümde araştırmanın veri seti, değişkenlerin belirlenmesi ve yöntemi yer almaktadır. Altıncı bölüm analiz sonucunda elde edilen bulgulara ve değerlendirmesine ayrılmıştır. Yedinci bölümde çalışmanın sonuçları verilmiştir.

\section{LITERATÜR İNCELEMESİ}

Türkiye'de faaliyet gösteren bankalar üzerine yapılan diğer çalışmalardan bizim çalışmamızın farklılığını ortaya koyabilmek için bu bölümde, Türkiye'deki bankalar üzerine yapılan çalışmalara öncelik verilmiştir.

Eleren ve Özgür (2006) Türkiye' de faaliyet gösteren dokuz yabancı bankanın etkinliğini 2001-2005 dönemi için incelemiştir. Mevduat ve Faiz Giderleri kalemlerinin girdi; Krediler ve Faiz Gelirleri kalemlerinin ise çıktı değişkenleri olarak yer aldığı çalışmada Veri Zarflama Analiz (VZA) yöntemi kullanılmıştır. Analiz sonucunda 2004 yılına kadar bankaların etkinliklerinde azalma eğilimi olduğu, bu yıldan sonra ise genel bir artış eğilimi olduğu tespit edilmiştir.

Demir ve Gençtürk (2006) İMKB' de işlem gören sekizi yerli, yedisi ise yabancı sermayeli olmak üzere toplam 15 bankanın etkinliklerini VZA yöntemi ile araştırmıştır. 2000-2006 dönemini kapsayan çalışmada, bankaların İşgücü, Sermaye ve Mevduat değerleri girdi, Krediler, Faiz Gelirleri ve Faiz Dışı Gelirler kalemleri ise çıktı değişkenleri olarak belirlenmiştir. Analiz sonucunda Türkiye ekonomisinde kriz dönemi olarak kabul edilen 2001 yılı dışında 2005 yılına kadar Türk sermayeli bankaların etkinliğinde artış gözlemlenirken 2005 ve 2006 yılında ise yabancı sermayeli bankaların göreceli olarak daha etkin olduğu tespit edilmiştir.

Özgür (2008) Türkiye'de faaliyet gösteren 3 kamu bankasının 2003-2007 dönemine ilişkin etkinliğini araştırdığı çalışmasında VZA yöntemini kullanmıştır. T.C. Ziraat Bankası A.Ş’nin en etkin kamu bankası olarak tespit edildiği çalışmada bankaların Mevduat, Personel Gideri ve Faiz Gideri kalemleri girdi; Krediler ve Faiz Gelirleri kalemleri ise çıktı değişkenleri olarak kullanılmıştır.

Seyrek ve Ata (2010) Türkiye' de faaliyet gösteren 20 mevduat bankasının etkinlik düzeylerini VZA yöntemini kullanarak araştırmıştır. 2003-2008 dönemini kapsayan çalışmada bankaların etkinlik skorları kullanılarak veri madenciliği teknikleri ile etkinlik tahmininde önemli olan performans ölçüleri belirlenmiştir. Toplam Mevduat, Faiz Gideri ve Faiz Dışı Giderler kalemlerinin girdi olarak yer aldığı araştırmada, Toplam Krediler, Faiz Gelirleri ve Faiz Dışı Gelirler kalemleri ise çıktı değişkenleri olarak seçilmiştir. Analiz sonuçlarına göre Toplam Krediler / Toplam Mevduatlar oranının banka etkinliği açısından temel belirleyici değişken olduğu saptanmıştır.

Demirbaş ve Sezgin (2010) küresel finansal krizin Türkiye, Amerika Birleşik Devletleri (ABD) ve Avrupa Birliği $(A B)$ 'ne üye ülkelerdeki bankaların etkinliklerinde meydana getirdiği değişimi 2006-2010 dönemi için araştırmıştır. $\mathrm{ABD}$ ve $\mathrm{AB}^{\prime}$ de aktif büyüklüğü açısından ilk 10 da yer alan mevduat bankaları ile Türkiye'den 14 bankanın verisinin kullanıldığı çalışmada etkinlik analizi hem aracılık hem de üretim yaklaşımı için çıktı odaklı ölçeğe göre sabit getiri (CRS) varsayımı altında uygulanmıştır. Üretim yaklaşımına göre bankaların Personel Giderleri / Toplam Aktifler, Faiz Dışı Faaliyet Giderleri / Toplam Aktifler oranları ile Şube Sayısı girdi; Toplam Mevduat / Toplam Aktifler ve Toplam Krediler / Toplam Aktifler oranları ise çıktı değişkenleri olarak seçilmiştir. Analiz sonucunda üretim ve aracılık yaklaşımına göre 2006 yılında Türkiye' deki bankaların etkinliğinin $A B D$ ve $A B$ bankalarına göre düşük olduğu, 2007 yılı sonrasında ise daha yüksek olduğu tespit edilmiştir. Kriz süreci $A B D$ ve $A B$ bankalarını daha derinden etkilemiş ve etkinlikleri düşmüştür.

Çelik ve Kaplan (2010) Türkiye bankacılık sektöründe 2002-2007 dönemi için etkinlik ve rekabet ilişkisini araştırmıştır. 32 ticari bankaya ilişkin verilerin kullanıldığı çalışmada uygulanan VZA yönteminin sonucuna göre bankaların ortalama etkinlik değerlerinin 2002 yılında 0.85, 2003 y1lında 0.77, 2004 yılında 0.81, 2005 yılında 0.89, 2006 yılında 0.90 ve 2007 yılında ise 0.82 olduğu tespit edilmiştir. Araştırmada bankaların etkinlik 


\section{S. Topak - Y. Alacaatlı 12/4 (2020) 4340-4350}

değerleri dikkate alındığında ise 2002 yılında 32 bankanın \%28'i, 2003 yılında \%25'i, 2004 yılında \%19'u, 2005 yılında \%32'si, 2006 yılında \%39'u, 2007 yılında ise \% 24'ünün etkin bir şekilde faaliyetlerini yürüttügü sonucuna varılmıştır. Çalışmada ulaşılan bir diğer sonuç ise 2005 ve 2006 yıllarında çalışma kapsamındaki bankalar içinde etkin banka sayısının diğer yıllara göre daha fazla olmasına bağlı olarak bu dönemlerde sektördeki rekabetin de yüksek olduğudur.

Akbalık ve Sırma (2013) Türkiye'deki yabancı bankaların 2008-2012 dönemi için etkinliğini araştırdı̆̆ı çalışmada, 10 adedi yabancı sermayeli olmak üzere toplam 23 bankanın verilerini kullanmıştır. Mevduat ve Faaliyet Giderleri kalemlerinin girdi, Krediler ve Faaliyet Gelirleri kalemlerinin ise çıtı değişkenleri olarak seçildiği çalışmada VZA yöntemi kullanılmıştır. Analiz sonucunda yabancı sermayeli bankaların etkinliğinin yıllar içinde azaldığı tespit edilmiştir.

Çarıkçı ve Akbulut (2020) Türkiye' de faaliyet gösteren 24 bankanın 2018 dönemine ilişkin verileri üzerinden yaptıkları çalışmada, VZA yöntemi ile bankaların etkinlik değerlerini ölçülmüştür. Analizde Aktif Toplam, Toplam Mevduat, Faiz Giderleri ve Şube Sayısı girdi, Krediler, Dönem Net Kârı ve Faiz Gelirleri kalemleri ise çıktı değişkeni olarak kullanılmıştır. Elde edilen sonuçlara göre bankaların genel verimlilik oranı \%95,7'dir. Sermaye yapılarına göre bankaların etkinlikleri karşılaştırıldığında ise yabancı sermayeli bankaların büyük ölçüde etkin olduğu, özel sermayeli bankalardan ise sadece birinin etkin olduğu, katılım bankalarının ise etkin olmadığı sonucuna varılmıştır.

Türkiye'de faaliyet gösteren bankalar üzerinde konuya ilişkin yapılan ve yukarıda bahsi geçen çalışmalar incelendiğinde kullanılan girdi ve çıktı değişkenleri farklılık göstermektedir. Çalışmamızın konusu üzerine farklı ülkelerde yapılan çok sayıdaki çalışma incelendiğinde de benzer bir durumla karşılaşılmaktadır. Saha ve Ravisankar (2000) Hindistan'da; Casu ve Molyneux (2003) Avrupa'daki beş ülkede (Fransa, Almanya, İtalya, İspanya ve İngiltere); Havrylchyk (2006) Polonya'da; Lin, Hsu ve Hsiao (2007) Tayvan'da; Paul ve Kourouche (2008) Avustralya'da; Nitoi (2009) Romanya'da; Anayiotos vd. (2010) gelişmekte olan 14 Avrupa ülkesinde; Shahid vd. (2010) Pakistan'da; Shafiee vd. (2014) İran'da; Mihaylova-Borisova (2014) Bulgaristan'da; Naumovska ve Cvetkoska (2016) Makedonya'da; Sufian ve Kamarudin (2016) Malezya'da; Grmanova ve Ivanova (2018) ise Slovakya'da faaliyet gösteren bankaların etkinliklerini araştırmıştır. Bu çalışmalardan Anayiotos vd. (2010) gelişmekte olan 14 Avrupa ülkesinde 84'ü yabancı sermayeli olmak üzere toplam 125 bankanın 2004, 2007 ve 2009 yılları için etkinliğini incelemiştir. Araştırmada bankaların Sermaye, Faiz Gideri ve Faaliyet Giderleri kalemleri girdi; Toplam Krediler, Vergi Öncesi Kar ve Menkul Kıymetler Portföyü ise çıktı değişkenleri olarak kullanılmışır. VZA yöntemi ile hesaplanan etkinlik değerlerine göre sırasıyla Çek Cumhuriyeti, Makedonya, Bulgaristan, Polonya, Litvanya ve Slovakya'daki bankaların en yüksek etkinlik değerlerine sahip olduğu; Arnavutluk, Ukrayna, Sırbistan, Hırvatistan, Romanya ve Macaristan'da faaliyet gösteren bankaların ise en düşük etkinlik değerlerine sahip bankalar olduğu tespit edilmiştir. Çalışmada ayrıca yabancı bankaların yerli bankalara göre daha etkin olduğu sonucuna varılmıştır.

\section{ARAŞTIRMANIN AMACI}

Bu çalışmanın amacı, Türkiye' de faaliyet gösteren mevduat bankalarının etkinliğinin araştırılması ve sermaye sahipliği açısından etkinliklerinin karşılaştııılmasıdır. Bu amaçla Türkiye'de faaliyet gösteren kamusal sermayeli, özel sermayeli ve yabancı sermayeli bankaların etkinlikleri incelenmiştir.

\section{VERI SETİ VE DEĞİŞKENLERİN BELİRLENMESİ}

Çalışmada Türkiye'de faaliyet gösteren üç adet kamusal sermayeli, beş adet özel sermayeli ve dört adet yabancı sermayeli olmak üzere toplam 12 mevduat bankasının 2010-2017 dönemine ilişkin finansal tablolarından temin edilen verileri kullanılmıştır. Bankacılık sektörünün toplam aktifleri içindeki payı \% 1 ve üzerinde olan bankalar çalışmaya dâhil edilmiştir. Araştırma kapsamındaki bankaların isimleri, 2017 yılsonu itibariyle aktif büyüklükleri ve bankacılık sektörü içindeki oranı Tablo 1'de yer almaktadır. 
Tablo 1. Çalışma Kapsamındaki Bankalar ve Aktif Büyüklükleri (31.12.2017)

\begin{tabular}{|l|c|c|}
\hline Banka İsimleri & $\begin{array}{c}\text { Aktif Büyüklük } \\
\text { (Milyon TL) }\end{array}$ & $\begin{array}{c}\text { Sektör Aktif Toplamından } \\
\text { Aldığı Pay }\end{array}$ \\
\hline \multicolumn{3}{|c|}{ Kamusal Sermayeli Bankalar } \\
\hline Türkiye Cumhuriyeti Ziraat Bankası A.Ş. & $434.274,51$ & $\% 14,03$ \\
\hline Türkiye Halk Bankası A.Ş. & $305.350,65$ & $\%$ 9,87 \\
\hline Türkiye Vakıflar Bankası T.A.O. & $270.571,71$ & $\%$ 8,74 \\
\hline Kamusal Sermayeli Bankalar Toplamı & $1.010 .196,87$ & $\% 32,67$ \\
\hline \multicolumn{2}{|c|}{ Özel Sermayeli Yerli Bankalar } \\
\hline Türkiye İş Bankası A.Ş. & $362.352,53$ & $\% 11,71$ \\
\hline Akbank T.A.Ş. & $316.030,87$ & $\% 10,21$ \\
\hline Yapı ve Kredi Bankası A.Ş. & $297.810,32$ & $\%$ 9,62 \\
\hline Türk Ekonomi Bankası A.Ş. & $85.758,23$ & $\%$ 2,77 \\
\hline Şekerbank T.A.Ş. & $31.346,46$ & $\% 1,01$ \\
\hline Özel Sermayeli Bankalar Toplamı & $1.093 .298,41$ & $\% 35,32$ \\
\hline \multicolumn{2}{|c|}{ Yabancı Sermayeli Bankalar } \\
\hline Türkiye Garanti Bankası A.Ş. & $325.232,27$ & $\% 10,51$ \\
\hline QNB Finansbank A.Ş. & $125.857,17$ & $\%$ 4,07 \\
\hline Denizbank A.Ş. & $121.048,28$ & $\%$ 3,91 \\
\hline ING Bank A.Ş. & $52.882,11$ & $\% 1,71$ \\
\hline Yabancı Sermayeli Bankalar Toplamı & $625.019,83$ & $\% 20,20$ \\
\hline 12 Bankanın Toplamı & $\mathbf{2 . 7 2 8 . 5 1 5 , 1 1}$ & $\%$ 88,19 \\
\hline Türk Bankacılık Sektörü & $\mathbf{3 . 0 9 5 . 0 3 9 , 1 7}$ & $\% \mathbf{1 0 0 , 0 0}$ \\
\hline
\end{tabular}

Kaynak: BDDK, 2018-b

Çalışmaya dâhil edilen 12 bankanın Türkiye bankacılık sektörünün toplam aktifleri içindeki payı \% 88,19'dur. Kamusal sermayeli bankaların sektör içindeki oranı \% 32,67; özel sermayeli bankalar ve yabancı sermayeli bankaların oranları ise sirasiyla $\% 35,32$ ve $\% 20,20$ 'dir.

Veri Zarflama Analizi yönteminin kullanıldığı araştırmada kullanılan girdi ve çıktı değişkenleri Tablo 2'de verilmiştir. Verilerin tamamı, bankaların Türkiye Bankalar Birliğinin resmi internet adresinden (https://verisistemi.tbb.org.tr/) temin edilen finansal tablolarından sağlanmıştıri.

Tablo 2. Araştırmada Kullanılan Değişkenler

\begin{tabular}{|l|l|}
\hline \multicolumn{1}{|c|}{ Girdiler } & \multicolumn{1}{c|}{ Çıktılar } \\
\hline Faiz Giderleri & Faiz Gelirleri \\
\hline Diğer Faaliyet Giderleri & Alınan Ücret ve Komisyonlar \\
\hline Özkaynaklar &
\end{tabular}

Analizde; Faiz Giderleri, Diğer Faaliyet Giderleri ve Özkaynaklar kalemleri girdi; Faiz Gelirleri ile Alınan Ücret ve Komisyon kalemleri ise çıktı olarak seçilmiştir. Değişkenler belirlenirken bankaların esas faaliyet alanı olan bankacılık faaliyetlerine ilişkin gider kalemleri girdi, esas faaliyetlerine ilişkin gelir kalemleri ise çıktı olarak belirlenmiştir. Özkaynakların girdi değişkenleri içerisinde yer almasının sebebi ise bankaların faaliyetlerini yürütmek için yapmış olduğu yatırımların finansmanında kullanılan özkaynakların şirkete bir maliyetinin bulunmasıdır. Ancak özkaynakların maliyeti, bir gider kalemi olarak gelir tablosunda yer almamaktadır. Finans teorisinde özkaynakların maliyetinin hesaplanmasına ilişkin geliştirilen çeşitli modellerin (Finansal Varlıkları Fiyatlama Modeli, Gordon Modeli, Arbitraj Fiyatlama Modeli) varsayımları dikkate alındığında, Türkiye' de faaliyet gösteren şirketlerin özkaynak maliyetinin söz konusu modellere göre belirlenmesi doğru bir yaklaşım değildir (Topak, 2018:102-104). Bu noktada bankaların özkaynakları arttıkça

'Sektör verileri BDDK'nın resmi internet adresinden(https://www.bddk.org.tr/ContentBddk/dokuman/veri 0014 39.pdf), bankalara ilişkin veriler TBB'nin resmi internet adresinden (https://www.tbb.org.tr/tr/bankacilik/banka-ve-sektorbilgileri/4 ) 15 Mart 2018 tarihinde temin edilmiştir. 
özkaynakların alternatif maliyet cinsinden tutarının da artacağı varsayılmış ve analizde özkaynakların maliyetini temsilen özkaynaklar tutarı girdi olarak kullanılmıştır.

\section{ARAŞTIRMANIN YÖNTEMI}

Çalışmada bankaların etkinlik düzeylerini belirlemek için Veri Zarflama Analiz (VZA) yöntemi kullanılmıştır. VZA, parametrik olmayan, doğrusal programlama temellerini esas alan ve seçilen karar birimleri arasında göreceli bir karşılaştırma yapılabilmesine imkân sağlayan bir yöntemdir. VZA kullanılarak yapılan çalışmalarda karar birimlerinin, bilgisayar programının ve veri setinin seçimi son derece önemlidir.

Çalışmada, "https://economics.uq.edu.au/files/3918/DEAP-xp1.zip" internet adresinden temin edilen DEAP 2.1 programı kullanılmıştır. VZA ile yapılan araştırmalarda minimum karar birimi sayısının kaç olması gerektiğine ilişkin farklı görüşler bulunmaktadır. Girdi sayısı (g) ve çıktı sayısı (ç) olarak sembolize edildiğinde, minimum karar birimi sayısı Tablo 3'de yer alan kriterlere göre farklılık göstermektedir.

Tablo 3. Minimum Karar Birimi Sayısının Belirlenmesi

\begin{tabular}{|l|c|c|}
\hline & $\begin{array}{c}\text { Minimum Karar Birimi } \\
\text { Sayısı (Formül) }\end{array}$ & $\begin{array}{c}\text { Minimum Karar } \\
\text { Birimi Sayısı }\end{array}$ \\
\hline Boussofiane vd. (1991) & $\left(\mathrm{g}^{*} c ̧\right)$ & $\left(3^{*} 2\right)=6$ \\
\hline Golany ve Roll $(1989)$ & $2^{*}(\mathrm{~g}+\mathrm{c})$ & $2^{*}(3+2)=10$ \\
\hline Dyson vd. (2001) & $\left(2^{*} \mathrm{~g}^{*} \mathrm{c}\right)$ & $\left(2^{*} 3^{*} 2\right)=12$ \\
\hline
\end{tabular}

Analizde üç adet girdi, iki adet çıktı değişkeni bulunmaktadır. Bu bilgilere göre analizde olması gereken minimum karar birim sayısı farklı kriterlere göre hesaplanarak Tablo 3'te verilmiştir. Araştırmanın veri setinde karar birim sayısı 12 bankadan oluşmaktadır. Kullanılan veri seti ve değişkenlerin sayısı dikkate alındığında Tablo 3'te belirtilen üç kritere göre de yapılan analiz gerekli koşulları sağlamaktadır.

Etkinlik analizinde kullanılan bir girdi değişkeni ile çıktıların tamamı arasındaki korelasyonun düşük olması durumunda, söz konusu girdinin araştırmada kullanılması anlamlı değildir (Yang, 2009). Girdi ve çıktı değişkenleri arasındaki korelasyon analizinin sonuçları Tablo 4'te yer almaktadır.

Tablo 4. Korelasyon Analizi

\begin{tabular}{|l|c|c|c|c|c|}
\hline Girdi / Çıktı & Özkaynaklar & $\begin{array}{c}\text { Faiz } \\
\text { Giderleri }\end{array}$ & $\begin{array}{c}\text { Diğer Faaliyet } \\
\text { Giderleri }\end{array}$ & $\begin{array}{c}\text { Faiz } \\
\text { Gelirleri }\end{array}$ & $\begin{array}{c}\text { Alınan Ücret } \\
\text { ve } \\
\text { Komisyonlar }\end{array}$ \\
\hline Özkaynaklar & 1,00 & & & & \\
\hline Faiz Giderleri & 0,91 & 1,00 & & & \\
\hline Diğer Faaliyet Giderleri & 0,95 & 0,90 & 1,00 & & \\
\hline Faiz Gelirleri & 0,96 & 0,98 & 0,95 & 1,00 & \\
\hline Alınan Ücret ve Komisyonlar & 0,85 & 0,70 & 0,89 & 0,77 & 1,00 \\
\hline
\end{tabular}

Korelasyon analizinin sonuçlarına göre çıtıların tamamı ile düşük korelasyona sahip bir girdi bulunmamaktadır. VZA yönteminde girdilerin çıktılar üzerindeki etkilerinin de aynı yönlü olması gerekmektedir (Pidd, 2012, 295). Tablo 4'te yer alan sonuçlara göre girdilerin çıtıllar üzerindeki etkileri aynı yönlüdür.

\section{BULGULAR}

\subsection{Veri Zarflama Analiz (Teknik Etkinlik) Sonuçları}

Çalışma kapsamındaki 12 mevduat bankasının 2010-2017 arasındaki faaliyet dönemlerine ilişkin VZA sonucunda elde edilen etkinlik değerleri Tablo 5 'de verilmiştir. Analizde teknik etkinlik değerleri her bir yıl için hesaplanmış ve etkinlik değerlerinin sekiz dönemlik aritmetik ortalaması alınarak bankalar sıralanmıştır. Tabloda koyu renkle yazılmış olan değerler, bankaların teknik açıdan ilgili dönemde etkin olmadığını göstermektedir. 
M. S. Topak - Y. Alacaatlı 12/4 (2020) 4340-4350

Tablo 5. Bankaların Teknik Etkinlik Değerleri

\begin{tabular}{|c|c|c|c|c|c|c|c|c|c|}
\hline Banka & 2010 & 2011 & 2012 & 2013 & 2014 & 2015 & 2016 & 2017 & $\begin{array}{l}2010-2017 \\
\text { Ortalama }\end{array}$ \\
\hline T.C. Ziraat Bankası A.Ş. & 1.000 & 1.000 & 1.000 & 1.000 & 1.000 & 1.000 & 1.000 & 1.000 & 1.000 \\
\hline Akbank T.A.Ş. & 1.000 & 1.000 & 1.000 & 1.000 & 1.000 & 1.000 & 1.000 & 1.000 & 1.000 \\
\hline Türkiye Garanti Bankası A.Ş. & 1.000 & 0.998 & 1.000 & 1.000 & 1.000 & 1.000 & 1.000 & 1.000 & 0.999 \\
\hline ING Bank A.Ş. & 1.000 & 0.990 & 1.000 & 1.000 & 1.000 & 1.000 & 1.000 & 1.000 & 0.999 \\
\hline QNB Finansbank A.Ş. & 1.000 & 1.000 & 1.000 & 1.000 & 0.977 & 1.000 & 1.000 & 1.000 & 0.997 \\
\hline Türkiye Halk Bankası A.Ş. & 1.000 & 1.000 & 1.000 & 0.966 & 1.000 & 1.000 & 1.000 & 1.000 & 0.996 \\
\hline Yapı ve Kredi Bankası A.Ş. & 1.000 & 1.000 & 1.000 & 1.000 & 0.967 & 1.000 & 1.000 & 1.000 & 0.996 \\
\hline Denizbank A.Ş. & 1.000 & 1.000 & 1.000 & 1.000 & 1.000 & 0.950 & 0.985 & 1.000 & 0.992 \\
\hline Türk Ekonomi Bankası A.Ş. & 1.000 & 0.905 & 1.000 & 1.000 & 1.000 & 1.000 & 1.000 & 0.969 & 0.984 \\
\hline Şekerbank T.A.Ş. & 0.914 & 1.000 & 1.000 & 0.908 & 0.942 & 1.000 & 1.000 & 1.000 & 0.971 \\
\hline Türkiye Vakıflar Bankası T.A.O. & 0.892 & 0.914 & 0.946 & 0.967 & 1.000 & 1.000 & 1.000 & 1.000 & 0.965 \\
\hline Türkiye İş Bankası A.Ş. & 0.876 & 0.880 & 0.874 & 0.891 & 0.914 & 0.923 & 0.928 & 0.905 & 0.899 \\
\hline 12 Bankanın Ortalaması & 0.974 & 0.974 & 0.985 & 0.978 & 0.983 & 0.989 & 0.993 & 0.990 & 0.983 \\
\hline
\end{tabular}

Analiz sonuçlarına göre T.C. Ziraat Bankası A.Ş. ve Akbank T.A.Ş. tüm dönemlerde etkinlik sınırı üzerinde faaliyet göstermektedirler. Bir başka ifade ile tüm dönemler için bu bankalar etkindir. Türkiye Halk Bankası A.Ş., Yapı ve Kredi Bankası A.Ş., ING Bank A.Ş., QNB Finansbank A.Ş. ve Türkiye Garanti Bankası A.Ş. bir dönem dışında, Denizbank A.Ş. ve Türk Ekonomi Bankası A.Ş. ise iki dönem dışındaki tüm dönemlerde teknik olarak etkindir. Sekiz yıllık faaliyet dönemi içinde Şekerbank T.A.Ş. beş dönemde etkin iken Türkiye Vakıflar Bankası T.A.O. dört dönemde teknik olarak etkin bulunmuştur. Türkiye İş Bankası A.Ş. ise analiz kapsamındaki hiçbir dönemde teknik olarak etkin değildir.

\subsection{Sermaye Sahipliği Açısından Bankalarda Etkinlik Karşılaştırması}

Sermaye sahipliği türüne göre bankaların etkinliğini inceleyebilmek amacıyla Tablo 6 hazırlanmıştır. Bu tabloda bankaların ortalama etkinlik değerleri ve etkinlik açısından başarı sırası ile etkin olduğu ve etkin olmadığı dönem sayıları birlikte verilmiştir. 
Tablo 6. Sermaye Sahipliğine Göre Bankaların Etkinlik Sonuçları

\begin{tabular}{|c|c|c|c|c|c|}
\hline & Banka İsimleri & $\begin{array}{c}\text { Ortalama } \\
\text { Etkinlik Değeri } \\
(2010-2017)\end{array}$ & $\begin{array}{c}\text { Etkinlik } \\
\text { Sirası }\end{array}$ & $\begin{array}{l}\text { Etkin } \\
\text { Olduğu } \\
\text { Dönem } \\
\text { Sayıs1 } \\
\end{array}$ & $\begin{array}{c}\text { Etkin } \\
\text { Olmadığı } \\
\text { Dönem } \\
\text { Sayısı } \\
\end{array}$ \\
\hline \multirow{3}{*}{ 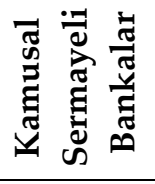 } & T.C. Ziraat Bankası A.Ş. & 1,000 & 1 & 8 & 0 \\
\hline & Türkiye Halk Bankası A.Ş. & 0,996 & 7 & 7 & 1 \\
\hline & Türkiye Vakıflar Bankası T.A.O. & 0,965 & 11 & 4 & 4 \\
\hline \multirow{5}{*}{ 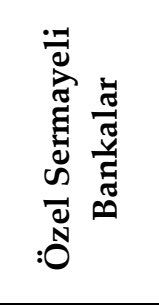 } & Akbank T.A.Ş. & 1,000 & 1 & 8 & 0 \\
\hline & Yapı ve Kredi Bankası A.Ş. & 0,996 & 6 & 7 & 1 \\
\hline & Türk Ekonomi Bankası A.Ş. & 0,984 & 9 & 6 & 2 \\
\hline & Şekerbank T.A.Ş. & 0,971 & 10 & 5 & 3 \\
\hline & Türkiye İş Bankası A.Ş. & 0,899 & 12 & 0 & 8 \\
\hline \multirow{4}{*}{ 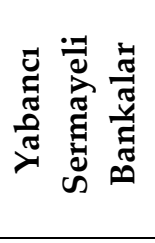 } & ING Bank A.Ş. & 0,999 & 3 & 7 & 1 \\
\hline & Türkiye Garanti Bankası A.Ş. & 0,999 & 4 & 7 & 1 \\
\hline & QNB Finansbank A.Ş. & 0,997 & 5 & 7 & 1 \\
\hline & Denizbank A.Ş. & 0,992 & 8 & 6 & 2 \\
\hline \multicolumn{2}{|c|}{ Türk Bankacılık Sektörü } & 0,983 & & 72 & 24 \\
\hline
\end{tabular}

Sermaye sahipliği açısından bankaların etkinlik sonuçları değerlendirildiğinde kamusal sermayeli bankalardan T.C. Ziraat Bankası 12 banka içerisinde en yüksek ortalama etkinlik değerine (Akbank T.A.Ş. ile birlikte) sahipken Türkiye Halk Bankası A.Ş. yedinci, Türkiye Vakıflar Bankası T.A.O. ise 11'nci sırada yer almaktadır. Çalışma kapsamındaki üç adet kamu bankasının etkinlik açısından başarı sırası değerlendirildiğinde, kamu bankalarının özel sermayeli bankalara ve yabancı sermayeli bankalara göre daha etkin olduğu ya da etkinlik düzeyinin daha düşük olduğunu söyleyemeyiz. Bu gruptaki üç bankadan T.C. Ziraat Bankası sektördeki en etkin iki bankadan birisi olurken, Türkiye Vakıflar Bankası T.A.O. ise etkinlik düzeyi en düşün ikinci banka olmuştur. Türkiye Halk Bankası A.Ş. ise ortalama etkinlik değeri açısından sektörde orta sıralarda yer almıştır.

Özel sermayeli bankalardan Akbank T.A.Ş. en yüksek ortalama etkinlik değerine (T.C. Ziraat Bankası ile birlikte) sahipken Türkiye İş Bankası A.Ş.'nin etkinlik değeri 12 banka içinde en düşük seviyededir. Söz konusu iki banka sermaye sahipliği acısından aynı grupta yer alırken esas faaliyetlerinin etkinliği açısından sekiz yıllık dönemin ortalamasına göre en başarılı ve en başarısız banka olmuşlardır. Bu sonuç, kamusal sermayeli bankalarda olduğu gibi özel sermayeli bankalar açsından da sermaye sahipliğine göre bankalarda etkinlik değerinin farklılaşabileceği görüşünü desteklememektedir. Bu grupta yer alan diğer bankalardan Yapı ve Kredi Bankası A.Ş. ortalama etkinlik değeri açısından altıncı, Türk Ekonomi Bankası A.Ş. ve Şekerbank T.A.Ş. ise sırasıyla dokuzuncu ve onuncu sıralarda yer almaktadır. Çalışma kapsamındaki 12 banka arasında, etkinlik değeri açısından son dört sırada yer alan bankalardan üçü özel sermayeli bankalardır.

Yabancı sermayeli bankalardan ING Bank A.Ş., Türkiye Garanti Bankası A.Ş. ve QNB Finansbank A.Ş. ortalama etkinlik değerleri açısından en başarılı üçüncü, dördüncü ve beşinci bankadır. Denizbank A.Ş. ise sekizinci sırada yer almaktadır. Bu grupta yer alan bankalar özel sermayeli bankalara göre etkinlik açısından genel olarak daha başarılıdır.

Sermaye sahipliğine göre banka türlerinin ortalama etkinlik değeri ile etkin oldukları dönem sayılarına ilişkin toplulaştırılmış bilgiler Tablo 7' de verilmiştir. Çalışmanın sekiz yıllık bir dönemi kapsaması nedeniyle tabloda üç adet kamu bankasına ilişkin toplam 24 dönem, beş adet özel sermayeli bankalara ilişkin 40 dönem ve dört adet yabancı sermayeli bankalara ilişkin 32 dönem olmak üzere toplamda 12 mevduat bankasının 96 dönemine ilişkin toplulaştırılmış sonuçları bulunmaktadır. 
Tablo 7: Sermaye Sahipliğine Göre Banka Gruplarının Etkinlik Sonuçları

\begin{tabular}{|l|c|c|c|c|c|}
\hline Bankalar & $\begin{array}{c}\text { Ortalama } \\
\text { Etkinlik } \\
\text { Değeri }\end{array}$ & $\begin{array}{l}\text { Etkin Olduğu } \\
\text { Dönem } \\
\text { Sayısı }\end{array}$ & $\begin{array}{c}\text { Etkin } \\
\text { Olmadığı } \\
\text { Dönem Sayısı }\end{array}$ & $\begin{array}{c}\text { Toplam } \\
\text { Dönem } \\
\text { Sayısı }\end{array}$ & $\begin{array}{c}\text { Etkin } \\
\text { Olduğu } \\
\text { Dönem (\%) }\end{array}$ \\
\hline Kamusal Sermayeli B. & 0.987 & 19 & 5 & 24 & 79 \\
\hline Özel Sermayeli B. & 0.970 & 26 & 14 & 40 & 65 \\
\hline Yabancı sermayeli B. & 0.997 & 27 & 5 & 32 & 84 \\
\hline Bankacılık Sektörü & $\mathbf{0 . 9 8 3}$ & $\mathbf{7 2}$ & $\mathbf{2 4}$ & $\mathbf{9 6}$ & $\mathbf{7 5}$ \\
\hline
\end{tabular}

Çalışma kapsamındaki bankaların 2010-2017 faaliyet dönemine ilişkin ortalama etkinlik değeri 0,983 olarak gerçekleşmiştir. Bankaların etkin olduğu dönem sayısı toplam dönem sayısının \% 75'ine eşittir. Bir başka ifade ile bankalar ortalama her dört dönemin üçünde faaliyetlerinde etkindirler. Ortalama etkinlik değeri kamusal sermayeli bankalarda 0,987; özel sermayeli bankalarda 0,970; yabancı sermayeli bankalarda 0,997'dir. Sermaye sahipliği açısından yapılan gruplandırmada, banka grupları açısında ortalama etkinlik değerleri arasında önemli bir fark bulunmamakla birlikte yabancı sermayeli bankalar ile kamusal sermayeli bankaların etkinlik değerlerinin ortalaması bankacılık sektörünün ortalamasının üzerinde gerçekleşirken özel sermayeli bankaların ortalama etkinlik değeri ise sektör ortalamasının altında kalmıştır.

Bankaların etkin olduğu dönem sayısının toplam dönem sayısı içindeki oranı incelendiğinde yabancı sermayeli bankaları için bu oranın \% 84, kamusal sermayeli bankalar için \% 79, özel sermayeli bankalar için ise \% 65 olarak gerçekleşmiştir. Özel sermayeli bankalar içinde yer alan Türkiye İş Bankası A.Ş.'nin çalışma kapsamındaki tüm dönemlerde teknik olarak etkin olmaması, bu grupta yer alan bankaların ortalama etkinlik değerlerinin diğer gruplara göre daha düşük çıkmasına neden olmuştur. Türkiye İş Bankası A.Ş.'nın sonuçları analize dâhil edilmeden özel sermayeli bankalar grubundaki diğer dört bankanın verileri üzerinden ortalama etkinlik değeri ve etkin olduğu dönem sayısı tekrar hesaplandığında, bu grupta yer alan bankalar kamusal sermayeli bankalar ve yabancı sermayeli bankaların ortalama değerleri arasında kalmaktadır. Özel sermayeli bankaların ortalama etkinlik değeri bu durumda $0,970^{\prime}$ den $0,988^{\prime}$ e, etkin olduğu dönemin toplam dönem sayısı içindeki oranı da \% 65'ten \% 81'e yükselmektedir.

\section{SONUÇ}

Türkiye'de faaliyet gösteren mevduat bankalarında etkinliğinin araştırılması ve sermaye sahipliği açısından bankaların etkinliklerinin karşılaştırılması amacıyla yapılan çalışmada, üç adet kamusal sermayeli, beş adet özel sermayeli ve dört adedi de yabancı sermayeli olmak üzere toplam 12 mevduat bankasının 2010-2017 dönemine ilişkin finansal tablolarından temin edilen verileri kullanılmıştır. Aktif büyüklüğü açısından çalışma kapsamındaki bankalar, 2017 yılsonu itibariyle Türkiye bankacılık sektörünün \% 88,16'sını oluşturmaktadır. Veri zarflama analiz tekniğinin kullanıldığı çalışmada Faiz Giderleri, Diğer Faaliyet Giderleri ve Özkaynaklar girdi; Faiz Gelirleri ile Alınan Ücret ve Komisyonlar ise çıktı değişkenleridir. Analiz sonucunda her bir yıl için bankaların teknik etkinlik değerleri elde edilmiş ve hesaplanan ortalama etkinlik değerleri üzerinden bankalar karşılaştırılmıştır. T.C. Ziraat Bankası A.Ş. ve Akbank T.A.Ş.'nin analiz kapsamındaki tüm dönemlerde teknik olarak etkin olduğu tespit edilirken, Türkiye İş Bankası A.Ş. ise analiz kapsamındaki tüm dönemlerde teknik olarak etkin değildir.

Sermaye sahipliği açısından banka türlerinin etkinliğini araştırmak için bankalar, kamusal sermayeli, özel sermayeli ve yabancı sermayeli bankalar şeklinde gruplandırılarak gruplar arası karşılaştırmalar yapılmıştır. Kamusal sermayeli bankalarda ortalama etkinlik değeri 0,987; özel sermayeli bankalarda 0,970 ve yabanc1 sermayeli bankalarda 0,997 olarak gerçekleşmiştir. Toplam dönem sayısı içinde bankaların etkin olduğu dönem sayısının oranı yabancı sermayeli bankalarda \% 84, kamusal sermayeli bankalarda \% 79, özel sermayeli bankalarda ise \% 65 olarak gerçekleşmiştir. Özel sermayeli bankalar grubunun gerek ortalama etkinlik değerinin gerekse de etkin olduğu dönemin toplam dönem içindeki oranının diğer gruplara göre görece düşük olmasının nedeni, Türkiye İş Bankası A.Ş.'nin çalışma kapsamındaki tüm dönemlerde teknik olarak etkin 
olmaması ve etkinlik değerinin düşük olmasıdır. Türkiye İş Bankası A.Ş.'nın sonuçları analiz dışında bırakıldığında özel sermayeli bankaların ortalama etkinlik değeri 0,988 , etkin olduğu dönemin toplam dönem içindeki oranı da \%81 e yükselmekte ve kamusal sermayeli bankalar ile yabancı sermayeli bankaların değerleri arasında kalmaktadır.

Analizde elde edilen sonuçlar bileştirildiğinde, Türkiye'de faaliyet gösteren mevduat bankalarında, sermaye sahipliği türüne göre bankaların etkinliklerinde fark yaratacak derecede önemli bir bulguya rastlanmamıştır.

\section{KAYNAKÇA}

Akbalık, M. \& Sırma İ. (2013).Türkiye'de yabancı bankaların etkinliği: veri zarflama analizi uygulaması. Finansal Araştırmalar ve Çalışmalar Dergisi, 4(8),1-16.

Anayiotos, G., Toroyan, H., \& Vamvakidis, A. (2010). The efficiency of emerging europe's banking sector before and after the recent economic crisis. Financial Theory and Practice, 34(3), 247-267.

Apergis, N., Filippidis, I., \& Economidou, C. (2007). Financial deepening and economic growth linkages: a panel data analysis. Review of World Economics, 143(1), 179-198.

Arabacı, H. (2018). Türkiye' de bankacılık sektörünün gelişimi. Meriç Uluslararası Sosyal ve Stratejik Araştırmalar Dergisi, 2(3), 25-42.

BDDK (2018-a). 2018 faaliyet raporu. https://www.bddk.org.tr/ContentBddk/dokuman/hakkinda _0003_10.pdf (Erişim Tarihi: 15 Mart 2018)

BDDK (2018-b). Türk bankacılık sektörü temel göstergeleri-Aralık 2018 https://www.bddk.org.tr/ContentBddk/dokuman/veri_0014_39.pdf (Erişim Tarihi: 15 Mart 2018)

Beck, T., \& Levine, R. (2004). Stock markets, banks, and growth: panel evidence. Journal of Banking $\mathcal{E}$ Finance, 28(3), 423-442.

Boussofiane, A., Dyson, R. G., \& Thanassoulis, E. (1991). Applied data envelopment analysis. European journal of operational research, 52(1), 1-15.

Casu, B., \& Molyneux, P. (2003). A comparative study of efficiency in european banking. Applied Economics, 35(17), 1865-1876.

Çarıkçı, O. \& Akbulut, F. (2020). Türk bankacılık sektörünün veri zarflama analizi ile etkinliğinin ölçülmesi, İşletme Araştırmaları Dergisi, 12 (1), 215-226.

Çelik, T., \& Kaplan, M. (2010). Türk bankacılık sektöründe etkinlik ve rekabet: 2002-2007. Sosyoekonomi, (2), 7.9-28.

Demir, Y., \& Gençtürk, M. (2006). İMKB'de işlem gören yerli ve yabancı bankaların göreli etkinliklerinin veri zarflama analizi ile ölçümü. Dokuz Eylül Üniversitesi İktisadi ve İdari Bilimler Fakültesi Dergisi, 21(2), 4974.

Demirbaş, M., \& Sezgin, F. H. (2010). Likidite krizi sürecinde amerika birleşik devletleri, avrupa birliği'ne üye ülkeler ve Türkiye' deki bankacılık sektörünün karşılaştırmalı etkinlik analizi: 2006-2010 dönemi. Gazi Üniversitesi İktisadi ve İdari Bilimler Fakültesi Dergisi, 12(3), 135-158.

Demirguc-Kunt, A., Feyen, E., \& Levine, R. (2012). The evolving importance of banks and securities markets (No. w18004). National Bureau of Economic Research.

Dyson, R. G., Allen, R., Camanho, A. S., Podinovski, V. V., Sarrico, C. S., \& Shale, E. A. (2001). Pitfalls and protocols in DEA. European Journal of operational research, 132(2), 245-259.

Eleren, A., \& Özgür, E. (2006). Türkiye'de yabancı sermayeli mevduat bankalarının veri zarflama yöntemi ile etkinlik analizlerinin yapılması. Afyon Kocatepe Üniversitesi İktisadi ve İdari Bilimler Fakültesi Dergisi, 8(2), 53-76.

Golany, B., \& Roll, Y. (1989). An application procedure for DEA. Omega, 17(3), 237-250.

Grmanová, E., \& Ivanová, E. (2018). Efficiency of banks in Slovakia: measuring by DEA models,“. Journal of International Studies Vol, 11(1),257-272.

Havrylchyk, O. (2006). Efficiency of the Polish banking Industry: foreign versus domestic banks. Journal of Banking \& Finance, 30(7), 1975-1996. 
King, R. G., \& Levine, R. (1993). Finance and growth: Schumpeter might be right. The Quarterly Journal of Economics, 108(3), 717-737.

Law, S. H., \& Singh, N. (2014). Does too much finance harm economic growth?. Journal of Banking \& Finance, 41, 36-44.

Lin, Y. H., Hsu, G. J., \& Hsiao, C. K. (2007). Measuring efficiency of domestic banks in Taiwan: application of data envelopment analysis and Malmquist index. Applied Economics Letters, 14(11), 821-827.

Mihaylova-Borisova, G. (2014). Bank efficiency in Bulgaria, International financial crisis and Eurozone debt crisis. Ikonomiceski Sotsialni Alternativi, (4), 17-24.

Naumovska, E., \& Cvetkoska, V. (2016). Efficiency of the Macedonian banking sector. Yugoslav Journal of Operations Research, 26(3).

Niţoi, M. (2009). Efficiency in the Romanian banking system: an application of data envelopment analysis. Romanian Journal of Economics, 29(2), 38.

Özgür, E.(2008). Kamu bankalarının finansal etkinliği. Sosyal Bilimler Dergisi, Cilt. 10, Sayı. 3, 247-260.

Paul, S., \& Kourouche, K. (2008). Regulatory policy and the efficiency of the banking sector in Australia. Australian economic review, 41(3), 260-271.

Pidd, M. (2012). Measuring the performance of public services: Principles and practice. Cambridge University Press.

Pradhan, R. P., Arvin, M. B., Hall, J. H., \& Bahmani, S. (2014). Causal nexus between economic growth, banking sector development, stock market development, and other macroeconomic variables: The case of ASEAN countries. Review of Financial Economics, 23(4), 155-173.

Saha, A., \& Ravisankar, T. S. (2000). Rating of Indian commercial banks: a DEA approach. European Journal of Operational Research, 124(1), 187-203.

Saldanli, A., \& Aydin, M. (2016). Bankacılık sektöründe karlılığı etkileyen faktörlerin panel veri analizi ile incelenmesi: Türkiye örneği. Ekonometri ve İstatistik Dergisi, (24), 1-9.

Seyrek, İ. H., \& Ata, H. A. (2010). Veri zarflama analizi ve veri madenciliği ile mevduat bankalarında etkinlik ölçümü. BDDK Bankacıllk ve Finansal Piyasalar, 4(2).67-84.

Shafiee, M., Sangi, M., \& Ghaderi, M. (2014). Bank performance valuation using dynamic DEA: A slacks-based measure approach. International Journal of Applied Operational Research, 4(3), 81-90.

Shahid, H., Rehman, R., Niazi, G. K., \& Raoof, A. (2010). Efficiencies comparison of Islamic and conventional banks of Pakistan. International Research Journal of Finance and Economics, 49(9), $24-42$.

Sufian, F., \& Kamarudin, F. (2016). Determinants of efficiency in the Malaysian banking sector: Does bank origins matter?. Intellectual Economics, 10(1), 38-54.

TBB Bankalarımız 2018 https://www.tbb.org.tr/Content/Upload/Dokuman/7604/Bankalarimiz_ 2018.pdf (Erişim Tarihi: 15 Mart 2018)

Topak, M. S., \& Çanakçioğlu, M. (2019). Banka performansının entropi ve copras yöntemi ile değerlendirilmesi: Türk bankacılık sektörü üzerine bir araştırma. Mali Çözüm Dergisi, 29, 107-132.

Topak, M.S. (2018). Ekonomik katma değer (EVA): hesaplanması ve performans ölçüsü olarak kullanılması, Türkmen Kitabevi.

Turgut, A., \& Ertay, H. İ. (2016). Bankacilık sektörünün ekonomik büyüme üzerindeki etkisi: Türkiye üzerine nedensellik analizi. Aksaray Üniversitesi İktisadi ve İdari Bilimler Fakültesi Dergisi, 8(4), 114-128.

Yang, Z. (2009, March). Bank branch operating efficiency: a DEA approach. In proceedings of the International MultiConference of Engineers and Computer Scientists (Vol. 2, pp. 18-20). 